\title{
Rapid screening of oil-rim reservoirs for development and management
}

\author{
Kazeem A. Lawal ${ }^{1}$ (1) - Asekhame U. Yadua ${ }^{2} \cdot$ Mathilda I. Ovuru $^{1} \cdot$ Oluchukwu M. Okoh $^{2} \cdot$ Stella I. Eyitayo $^{1}$. \\ Saka Matemilola ${ }^{1}$. Olugbenga Olamigoke ${ }^{3}$
}

Received: 11 September 2019 / Accepted: 24 November 2019 / Published online: 2 December 2019

(c) The Author(s) 2019

\begin{abstract}
As an improvement over existing screening techniques, we introduce the relative mobile energy of primary gas-cap to the aquifer $\left(E_{\mathrm{gw}}\right)$ as a new parameter for characterizing the performance of oil-rim reservoirs. $E_{\mathrm{gw}}$ integrates key static and dynamic reservoir properties. To account for the time value of production, the framework allows maximizing the discounted recovery factor (DRF) of oil, gas or total hydrocarbon as the objective function. Employing detailed simulations of different well-defined oil-rim models, DRFs of oil, gas and total hydrocarbons have been correlated against $E_{\mathrm{gw}}$ for common development concepts and well types. These correlations have resulted in a new screening technique for both green and brown oil-rim reservoirs. In addition to presenting simple generic charts for quick evaluation of oil-rim reservoirs, the main contributions of this work include the introduction of $E_{\mathrm{gw}}$ as a new performance-characterizing parameter, and the flexibility to consider the DRF of any of oil, gas or total hydrocarbon as the basis for screening an oil-rim reservoir for development planning and field management. Using the example of a brown oil-rim reservoir, the applicability and robustness of the new screening technique are demonstrated.
\end{abstract}

Keywords Oil rim · Gas-cap reservoirs $\cdot$ Thin oil column $\cdot$ Saturated reservoirs $\cdot$ Relative mobile energy

Kazeem A. Lawal

kazeem.lawal@ first-epdc.com

Asekhame U. Yadua

asekhame.yadua@nnpcgroup.com

Mathilda I. Ovuru

mathilda.ovuru@first-epdc.com

Oluchukwu M. Okoh

oluchukwu.okoh@nnpcgroup.com

Stella I. Eyitayo

stella.eyitayo@first-epdc.com

Saka Matemilola

saka.matemilola@first-epdc.com

Olugbenga Olamigoke

o.olamigoke@unilag.edu.ng

1 FIRST Exploration and Petroleum Development Company (FIRST E\&P), Lagos, Nigeria

2 Nigerian Petroleum Development Company (NPDC), Benin City, Nigeria

3 Department of Chemical and Petroleum Engineering, University of Lagos, Lagos, Nigeria

\section{List of symbols}

$B_{\mathrm{gi}} \quad$ Initial gas formation volume factor $\left(\mathrm{rm}^{3} / \mathrm{sm}^{3}\right)$

$B_{\text {oi }}$ Initial oil formation volume factor $\left(\mathrm{rm}^{3} / \mathrm{sm}^{3}\right)$

$E_{\mathrm{g}}$ Initial mobile energy of the gas cap $\left(\mathrm{m}^{6} \mathrm{~Pa}^{-1} \mathrm{~s}^{-1}\right)$

$E_{\mathrm{o}} \quad$ Initial mobile energy of the oil $\operatorname{rim}\left(\mathrm{m}^{6} \mathrm{~Pa}^{-1} \mathrm{~s}^{-1}\right)$

$E_{\mathrm{w}} \quad$ Initial mobile energy of the aquifer $\left(\mathrm{m}^{6} \mathrm{~Pa}^{-1} \mathrm{~s}^{-1}\right)$

$G_{\mathrm{i}} \quad$ Free gas initially in place at standard conditions $\left(\mathrm{sm}^{3}\right)$

$G_{\mathrm{r}} \quad$ Free gas initially in place at reservoir conditions $\left(\mathrm{rm}^{3}\right)$

$h_{\mathrm{g}} \quad$ Initial gas column effective thickness (m)

$h_{o} \quad$ Initial oil column effective thickness (m)

$h_{\mathrm{w}} \quad$ Initial aquifer effective thickness (m)

$i \quad$ Producing year counter (dimensionless)

$K \quad$ Absolute permeability $\left(\mathrm{m}^{2}\right)$

$K_{\mathrm{rg}} \quad$ End-point relative permeability to gas at residual oil saturation (fraction)

$K_{\text {ro }} \quad$ End-point relative permeability to oil at connate water saturation (fraction)

$K_{\text {rw }} \quad$ End-point relative permeability to water at residual oil saturation (fraction)

$m \quad$ Ratio of initial gas-cap-gas reservoir volume to initial reservoir oil volume (dimensionless) 
$M \quad$ Ratio of initial aquifer water volume to initial reservoir oil volume (dimensionless)

$M_{\mathrm{g}} \quad$ Gas mobility $\left(\mathrm{m}^{3} \mathrm{~Pa}^{-1} \mathrm{~s}^{-1}\right)$

$M_{\mathrm{o}} \quad$ Oil mobility $\left(\mathrm{m}^{3} \mathrm{~Pa}^{-1} \mathrm{~s}^{-1}\right)$

$M_{\mathrm{w}} \quad$ Water mobility $\left(\mathrm{m}^{3} \mathrm{~Pa}^{-1} \mathrm{~s}^{-1}\right)$

$n \quad$ Total number of production years (dimensionless)

$N_{\mathrm{i}} \quad$ Oil initially in place at stock-tank conditions $\left(\mathrm{sm}^{3}\right)$

$N_{\mathrm{r}} \quad$ Oil initially in place at reservoir conditions $\left(\mathrm{rm}^{3}\right)$

$P_{\mathrm{i}} \quad$ Initial reservoir pressure $(\mathrm{Pa})$

$P_{\text {ri }} \quad$ Reservoir pressure at which production switches from oil to gas-cap blowdown (Pa)

$r \quad$ Discount rate (fraction)

$R_{\mathrm{si}} \quad$ Initial solution gas-oil ratio, $\left(\mathrm{m}^{3} / \mathrm{m}^{3}\right)$

$W_{\mathrm{i}} \quad$ Aquifer water initially in place at stock-tank conditions $\left(\mathrm{sm}^{3}\right)$

$W_{\mathrm{r}} \quad$ Aquifer water initially in place at reservoir conditions $\left(\mathrm{rm}^{3}\right)$

$\mu_{\text {gi }} \quad$ Initial gas viscosity (Pa s)

$\mu_{\mathrm{oi}} \quad$ Initial oil viscosity ( $\mathrm{Pa} \mathrm{s}$ )

$\mu_{\mathrm{wi}} \quad$ Initial water viscosity (Pa s)

\section{Introduction}

In general, any saturated oil accumulation in a porous medium underlain by an aquifer is an oil-rim reservoir. More specifically, an oil-rim reservoir is characterized by an oil zone overlain by a relatively large and active gas cap while, at the same time, underlain by a relatively large and active aquifer. Depending on the geometry of the gas cap and aquifer that envelope the oil zone, an oil rim can be of a doughnut or pan-cake type (Fig. 1). Because the dynamics of gas cap and aquifer in the doughnut and pan-cake oil-rim configurations are not necessarily the same, the evaluation and management of oil-rim reservoirs are complex, computationally intensive and less straightforward (John et al. 2019; Elharith et al. 2019; Fan et al. 2015; Lawal et al. 2010; Silva and Dawe 2010).

As a result of the active gas cap and aquifer, the exploitation of oil rims is often associated with complex production problems, which are attributed to an early breakthrough of gas and/or water (Jaoua and Rafiee 2019; John et al. 2019; John 2017; Masoudi et al. 2013). Most oil-rim developments are bedevilled by gas and water coning, both of which are detrimental to well productivity and ultimate recovery. The early and sustained production of these unwanted associated fluids increases the operating expenses related to handling gas and water produced per unit volume of oil recovered, hence eroding project value. Because coning rates are usually below economic thresholds, the strategy of limiting oil offtake below gas and water coning rates has not recorded significant success in practice (Balogun et al. 2015; Dilib et al. 2015; Yeoh 2014; Lawal et al. 2010; Kromah and Dawe 2008; Uwaga and Lawal 2006).

From a development planning standpoint, there are always questions about the most appropriate development concept and well type for a given oil-rim reservoir. Another common puzzle is the best timing to commence dedicated gas development by blowing down the remaining gas cap after the oil resources might have been exploited to some techno-economic limits. Recognizing that both oil and gas are prospective revenue sources, it is not uncommon for the developers of oil-rim reservoirs to have extensive debates on the following alternative development options at early stages: (1) develop oil first, and the gas later; (2) develop only the gas, essentially ignoring the oil; (3) develop both oil and gas concurrently, but produce gas intermittently; and (4) develop and produce both oil and gas concurrently.
Fig. 1 Configurations of oil-rim reservoirs in plan and cross section, where GOC and OWC are the gas-oil contact and oil-water contact, respectively (Lawal et al. 2010)

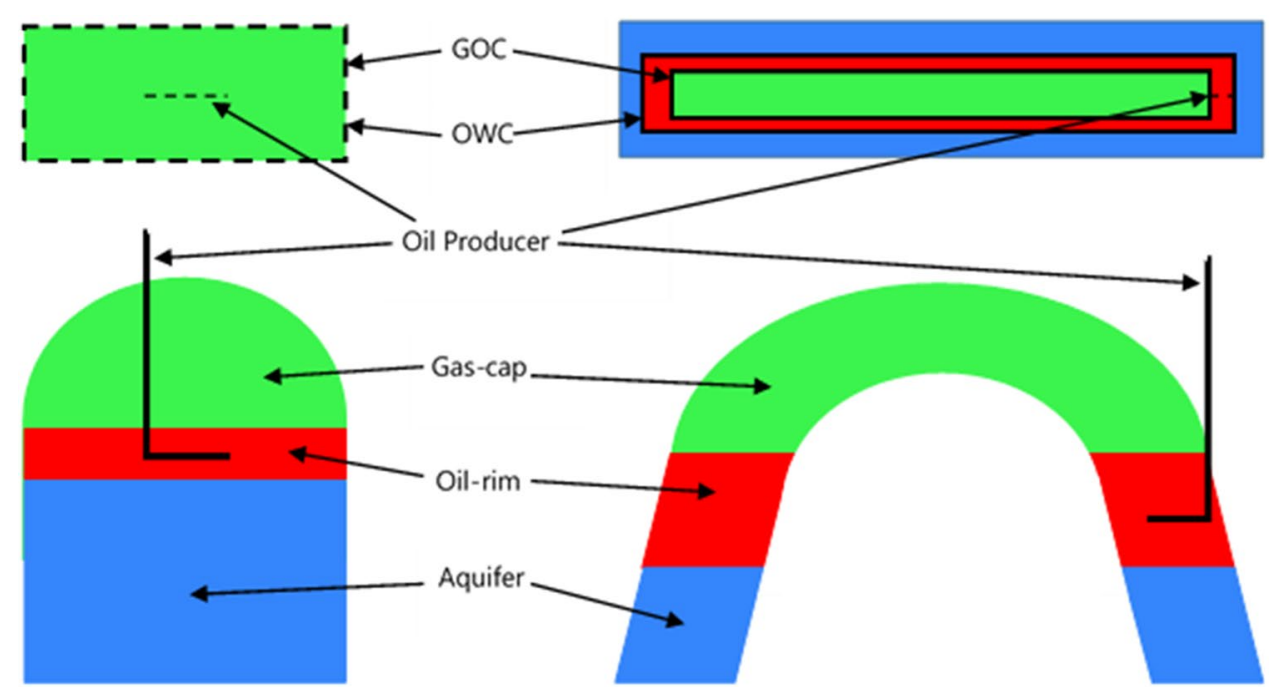

(a) "Doughnut" Structure (b) "Pancake" Structure 
The arguments and counter-arguments for these options are diverse and tend to vary from one case to the other, underscoring the need to improve the current body of knowledge on this subject for better decision-making (Obidike et al. 2019a, b; Thomas and Bratvold 2015; Garimella et al. 2010; Clarke et al. 2006; Uwaga and Lawal 2006).

Maximizing the recovery of either or both oil and gas in an oil-rim reservoir is clearly an optimization problem. In searching for an optimum solution, the rigorous evaluation of the various development options often requires extensive reservoir simulation studies. This optimization problem entails multiple variables, which include geologic, engineering, economic, regulatory and operational factors (Ziablitckaia et al. 2019; Elharith et al. 2019; Ogolo et al. 2018; Dilib et al. 2015; Thomas and Bratvold 2015; Chan et al. 2014; Uwaga and Lawal 2006). These variables usually exhibit varied dependencies, thereby complicating the problem of selecting the most appropriate combination of well type, development concepts and production constraints. The solution to this problem is computationally intensive, with the attendant delay in decision-making, yet it does not guarantee the uniqueness and optimality of the outcome and recommendations.

To partly address the foregoing challenge of time-consuming evaluation and its negative impacts on turn-around time for business decisions, the investigation of oil-rim reservoirs often entails the use of simple screening methods to narrow the search space, as against exploring the large solution space. For this purpose, different screening techniques, which can broadly be classified as empirical, numerical and analytical, have been published and applied with mixed success (John et al. 2019; Obidike et al. 2019a; Olamigoke and Isehunwa 2019; Balogun et al. 2015; Yeoh 2014; Lawal et al. 2010; Olamigoke and Peacock 2009; Kabir et al. 2004; Vo et al. 2000; Irrgang 1994). The primary objective of these models is to provide simple guidelines on the feasibility of oil-rim exploitation and the appropriate development concept, especially at the early stages of field studies and development planning. A review of some of these models and their relative drawbacks has been documented by other workers (Lawal et al. 2010).

Vo et al. (2000) used performance data from some horizontal wells completed in oil-rim reservoirs in Indonesia to derive a mathematical function relating oil recovery factor (RF) to oil column thickness. Earlier, Irrgang (1994) analysed performance data from some conventional wells completed in a limited number of oil-rim reservoirs in Australia to derive a correlation for estimating oil ultimate recovery (UR) as a function of some petrophysical and fluid properties. None of these empirical methods provides a basis for comparing the effects of different well types, nor can they be used to assess the feasibility of exploiting either the gas cap or maximizing both oil and gas recovery. In addition, these correlations do not provide any clue on either the timing or the sequence for developing the oil and gas resources.

Introducing the idea of expanding mobile energy as the basis for oil recovery, Lawal et al. (2010) derived an expression for estimating oil RF of an oil-rim reservoir. In their work, it was assumed that oil recovery was linearly proportional to the energy expended by the reservoir. They argued that the magnitude of this reservoir drive energy is governed by the pressure-volume work done by an expanding gas cap. However, restricting oil offtake to the gas coning rate, ignoring aquifer drive and non-consideration of possible production acceleration are some drawbacks of their proposition.

With the aid of numerical reservoir simulations, Yeoh (2014) studied the dependencies of oil RF on horizontal permeability, vertical-to-horizontal permeability ratio (i.e. permeability anisotropy), oil viscosity, gas-cap size, aquifer size, well spacing, oil rate and initial oil thickness for a thin oil-rim reservoir. This effort yielded a correlation that relates oil RF to these variables. Among other shortcomings, the work was restricted to oil-only development. In addition, the correlation does not provide guidance for using production acceleration to discriminate between competing development concepts and well types.

John (2017) and then John et al. (2019) used experimental design to create 17 different numerical experiments to study the effects of seven independent variables on oil RF from oil-rim reservoirs. Parameter screening and response-surface methodology were then applied to select the most important variables and establish relationships between them and RF, for three different development concepts vis-à-vis oil-thengas (OTG), concurrent oil and gas (COG), as well as gasonly development. However, the studies did not consider the oil-only development option, nor did they provide a clear heuristic on when to switch from oil to gas-cap blowdown in the case of an OTG option. Additionally, their use of ultimate oil RF as the objective variable precludes the resulting models from accounting for differences in production acceleration, which is a proxy for economic performance, among the development options.

Following a critical appraisal of previous works on the evaluation and development of oil-rim reservoirs, Obidike et al. (2019a) reported several key findings, including areas of improvement. They noted the lack of consensus on the definition of oil-rim reservoirs, as well as the primary factors that drive the development and management of these resources. More instructive, they queried the general focus on technical factors, at the expense of equally important non-technical factors (commercial and strategic), in the current practices of screening oil-rim reservoirs for exploitation. In line with this thought, Thomas and Bratvold (2015) earlier argued that maximizing the production time of profitable oil at the expense of the associated gas-cap does not necessarily guarantee the return of maximum value from an oil-rim development project.

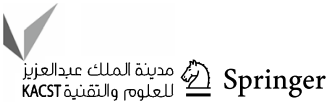


Rather, they advocated for a real-options approach, where the maximum value, hence business decisions, would be driven by expected revenue and cost profiles linked to either or both oil and gas, as well as the timing of their developments. Therefore, we opine that a screening model that is simple, yet incorporating relevant technical and non-technical factors, would be value added to both the theoretical and practical aspects of the assessment, development and management of oil-rim reservoirs.

Considering the limitations of existing methods, we introduce a different approach for screening development concepts for oil-rim reservoirs. A new parameter, consisting of relevant technical and non-technical (economic) factors, is proposed for characterizing the performance of an oil-rim reservoir for different development options and well types. As a further improvement over previous approaches, we employ discounted recovery factor, rather than either absolute recovery factor or ultimate recovery, as the basis for screening. In addition, unlike existing formulations that focus on the recovery of just oil as the hydrocarbon of interest, our new guideline offers the flexibility to consider any of oil, gas or total hydrocarbon as the primary driver for screening the development options for an oil-rim reservoir.

In essence, this paper presents a new technique and workflow that employs basic and readily available rock and fluid properties to identify the optimum development concept(s) in terms of primary hydrocarbon target and, where necessary, the suitable time to commence the conscious exploitation of the secondary hydrocarbon fluid in oil-rim reservoirs. More specifically, clear quantitative guidelines are provided to screen the various oil-rim reservoir development options vis-à-vis oil-only, COG, OTG and, by extension, gas-only (i.e. gas-cap blowdown). Additionally, the new propositions account for the effects of vertical versus horizontal wells and provide quantitative insights into how these well types influence the performances of the aforementioned development options.

We envisage that these contributions to the existing body of knowledge on this subject would help the engineer to quickly narrow the solution space and facilitate decision-making on the development of oil-rim reservoirs. The simple charts generated from this work should aid the rapid comparison of the potential performances of different oil-rim reservoirs under the same development concept, as well as the evaluation of different development concepts in the same oil-rim reservoir. The results should also be relevant for the management and potential re-development of producing oil-rim reservoirs.

\section{Model formulation}

We characterize the performance of oil-rim reservoirs with a parameter that incorporates both in situ energy and mobility of the individual fluids (phases). Thus, as a major improvement over most of the existing techniques, the new performance-characterizing parameter reflects both the static and dynamic properties of an oil-rim reservoir. The following are the premises that underpin the theoretical framework of our proposition.

- The ease of recovery of a phase is proportional to its mobile (disposable) energy.

- The product of the initial volume in-place and mobility of a phase is a measure of its (disposable) energy. Accordingly, expressions for the initial in situ mobile energies of the individual phases are required.

\section{Initial gas-cap mobile energy}

Based on the foregoing definitions, the initial mobile energy of the gas cap at reservoir conditions is given by the following expressions:

$E_{\mathrm{g}}=G_{\mathrm{r}} M_{\mathrm{g}}$

$E_{\mathrm{g}}=\left(G_{\mathrm{i}} B_{\mathrm{gi}}\right)\left(\frac{K k_{\mathrm{rg}} h_{\mathrm{g}}}{\mu_{\mathrm{gi}}}\right)$,

where $G_{\mathrm{r}}=$ free gas initially in place at reservoir conditions, $M_{\mathrm{g}}=$ in situ mobility of free gas, $G_{\mathrm{i}}=$ free gas initially in place at standard conditions, $B_{\text {gi }}=$ initial gas formation volume factor, $K=$ absolute permeability, $K_{\mathrm{rg}}=$ end-point relative permeability to gas at residual oil saturation, $h_{\mathrm{g}}=$ initial gas column effective thickness, and $\mu_{\mathrm{gi}}=$ initial gas viscosity. The units of these quantities are defined in the nomenclature section.

\section{Initial oil-rim and aquifer mobile energies}

Following from that of the gas cap, the initial mobile energies of the oil rim and aquifer at in situ conditions are given by the following expressions, respectively:

$$
\begin{aligned}
& E_{\mathrm{o}}=\left(N_{\mathrm{i}} B_{\mathrm{oi}}\right)\left(\frac{K k_{\mathrm{ro}} h_{\mathrm{o}}}{\mu_{\mathrm{oi}}}\right), \\
& E_{\mathrm{w}}=W_{\mathrm{i}}\left(\frac{K k_{\mathrm{rw}} h_{\mathrm{w}}}{\mu_{\mathrm{wi}}}\right),
\end{aligned}
$$

where it is assumed that water is incompressible. The various quantities and their units are defined in the nomenclature section.

In principle, the mobile energy of a displacing phase (gas or water) relative to that of oil is a measure of the threat posed by that phase to oil recovery. Accordingly, we estimate the following as measures of the initial strengths of 
each of the gas-cap and aquifer in comparison with that of the oil rim

\section{Relative mobile energy of the gas cap}

This is the ratio of initial mobile energy of the gas-cap to that of the underlying oil rim. The combination of Eqs. 1b and 2 yields the following expression for the mobile energy of the primary gas-cap relative to that of the oil rim.

$E_{\mathrm{go}}=\frac{G_{\mathrm{i}} B_{\mathrm{gi}} k_{\mathrm{rg}} h_{\mathrm{g}} \mu_{\mathrm{oi}}}{N_{\mathrm{i}} B_{\mathrm{oi}} k_{\mathrm{ro}} h_{\mathrm{o}} \mu_{\mathrm{gi}}}$

\section{Relative mobile energy of the aquifer}

This is the ratio of initial mobile energy of the aquifer to that of the overlying oil rim. Similarly, the ratio of Eqs. 3 to 2 results in the mobile energy of the aquifer in relation to the oil rim.

$E_{\mathrm{wo}}=\frac{W_{\mathrm{i}} k_{\mathrm{rw}} h_{\mathrm{w}} \mu_{\mathrm{oi}}}{N_{\mathrm{i}} B_{\mathrm{oi}} k_{\mathrm{ro}} h_{\mathrm{o}} \mu_{\mathrm{wi}}}$.

In practice, free gas and water are the major threats to the exploitation of oil resources from oil-rim reservoirs. Therefore, with the objective of maximizing oil recovery, we consider the relative energy of gas-cap to aquifer $\left(E_{\mathrm{gw}}\right)$ as a reasonable measure of the net threat posed to oil recovery. Hence, we introduce a new quantitative performance indicator $E_{\mathrm{gw}}$, which we define as the relative mobile energy of gas-cap to aquifer at initial reservoir conditions. A simple ratio of Eqs. 4 to 5 defines the dimensionless quantity $E_{\mathrm{gw}}$.

$E_{\mathrm{gw}}=\frac{G_{\mathrm{i}} B_{\mathrm{gi}} k_{\mathrm{rg}} h_{\mathrm{g}} \mu_{\mathrm{wi}}}{W_{\mathrm{i}} k_{\mathrm{rw}} h_{\mathrm{w}} \mu_{\mathrm{gi}}} \equiv \frac{m k_{\mathrm{rg}} h_{\mathrm{g}} \mu_{\mathrm{wi}}}{M k_{\mathrm{rw}} h_{\mathrm{w}} \mu_{\mathrm{gi}}}$

where $m=$ ratio of initial gas cap reservoir volume to initial reservoir oil volume (dimensionless), and $M=$ ratio of initial aquifer water volume to initial reservoir oil volume (dimensionless).

From Eq. 6, the case of $E_{\mathrm{gw}}>1$ suggests that gas-cap would be the dominant drive mechanism; hence, gas is expected to pose a greater threat to oil production than water. Conversely, the scenario of $E_{\mathrm{gw}}<1$ indicates that the aquifer would be the dominant drive mechanism; thus, water production would pose a greater threat to oil recovery. In the case of $E_{\mathrm{gw}}=1$, it is expected that oil recovery would be equally vulnerable to the threats of both gas and water influx.

It is worthy of note that the foregoing derivations and final expression (Eq. 6) are premised on the simple assumption that the gas-cap, oil rim and aquifer are characterized by the same average absolute permeability $K$. But this is not often the case. Therefore, in cases where the gas-cap and aquifer have different absolute (average) permeabilities, the performance-characterizing parameter is modified to take the following form:

$E_{\text {gw_modified }}=\frac{G_{\mathrm{i}} B_{\mathrm{gi}} k_{\mathrm{rg}} K_{\mathrm{g}} h_{\mathrm{g}} \mu_{\mathrm{wi}}}{W_{\mathrm{i}} k_{\mathrm{rw}} K_{\mathrm{w}} h_{\mathrm{w}} \mu_{\mathrm{gi}}} \equiv \frac{m k_{\mathrm{rg}} K_{\mathrm{g}} h_{\mathrm{g}} \mu_{\mathrm{wi}}}{M k_{\mathrm{rw}} K_{\mathrm{w}} h_{\mathrm{w}} \mu_{\mathrm{gi}}}$,

where $K_{\mathrm{g}}$ and $K_{\mathrm{w}}$ are the average absolute permeabilities of the gas-cap and aquifer zones, respectively.

\section{Numerical experiments}

After deriving a performance-characterizing parameter, the next step is to ascertain the robustness of this parameter in predicting the behaviour of oil-rim reservoirs under different development scenarios. To accomplish this objective, we explore possible functional relationships between oil recovery and $E_{\mathrm{gw}}$. Based on the insights gained from these relationships, we propose simple guidelines for developing and managing oil-rim reservoirs.

Well-controlled numerical experiments are used to explore the functional relationships. Among other considerations, these experiments investigate the effects of completion type (horizontal vs. vertical well), development scenario (oil-only, OTG vs. COG), as well as some common production constraints.

\section{Numerical model}

To keep the problem tractable, we employ a simple box reservoir model, characterized by $50 \times 50 \times 167$ simulation cells. Each cell has an approximate dimension of $20 \mathrm{~m} \times 20 \mathrm{~m} \times 3 \mathrm{~m}$. The choice of cell area dimension of $20 \mathrm{~m} \times 20 \mathrm{~m}$ was arbitrary, but finer than the cell dimensions of $50 \mathrm{~m} \times 50 \mathrm{~m}$ and $100 \mathrm{~m} \times 100 \mathrm{~m}$ typically used to simulate realistic reservoirs in practice (Lawal et al. 2016, 2017; Dilib et al. 2015; Uwaga and Lawal 2006; Kabir et al. 2004). However, prior grid sensitivity tests suggested that a $3 \mathrm{~m}$ layer thickness was adequate to achieve computational efficiency without significant numerical artefacts for this specific model. Note that this model thickness $(500 \mathrm{~m})$ includes the gas-cap, oil rim and a bottom aquifer. In all the cases examined, in order to keep all the model features under control, no external analytical aquifer was attached to the model. The numerical aquifer models (grid blocks in the water leg) were always kept active to simulate aquifer dynamics.

This generic model is characterized by a constant porosity of $25 \%$ in the gas-cap, oil-rim and aquifer zones. The ratio of vertical to horizontal permeability $\left(K_{\mathrm{v}} / K_{\mathrm{h}}\right)$ in the three zones was 0.1 . Although the choice of $25 \%$ porosity and permeability ratio of 0.1 in this work is arbitrary, these numerical estimates are not uncommon for typical

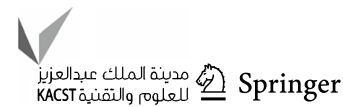


reservoirs in the Niger Delta and elsewhere (John et al. 2019; Elharith et al. 2019; Ogolo et al. 2018; Olabode et al. 2018; Udoh et al. 2018; Obinna et al. 2016). For simplicity, both the porosity and $K_{\mathrm{v}} / K_{\mathrm{h}}$ remain unchanged for all the cases investigated. The fluid model is descriptive of slightly volatile oil, while the relative permeability functions are characteristic of a water-wet system. The reservoir is hydrostatic. The assumption of slightly volatile oil in our generic reservoir is not uncommon for most oilrim reservoirs (John et al. 2019; Ziablitckaia et al. 2019; Ogolo et al. 2018).

Figure 2 shows a 2D view of the box model, showing an example gas producer and a horizontal oil producer. For simplicity, the box model used in this study approximates the "doughnut" structure of an oil rim (Fig. 1). From our experience, due to gravity effects, this doughnut configuration often poses greater challenges to oil recovery from an oil rim than its pan-cake counterpart under similar conditions. Therefore, in principle, the insights gained from this work should yield relatively conservative results, especially when applied to oil-rim reservoirs that are more consistent with a "pan-cake" structure (Fig. 1).

\section{Subsurface realizations}

To capture the effects of different relative mobile energies on reservoir performance, several cases of gas, oil and aquifer thickness were considered. The geometry of the fluid zones varied in different case sets. Hence, the initial in-place gas, oil and water volumes differ among cases. Table 1 gives an outline of the initial fluid distribution for all the case sets evaluated. For each case set, three different average absolute permeability states were studied. These states are 200, 800 and $1500 \mathrm{mD}$. Thus, the

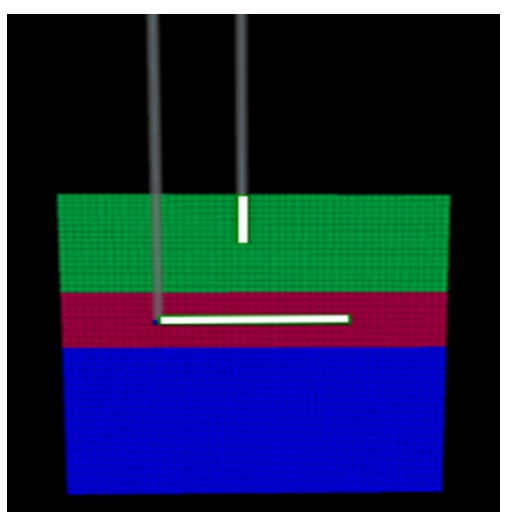

Fig. 2 A 2D view of the box model, showing the gas (green), oil (red) and water (blue) zones at initial conditions. The white lines depict the completion intervals for the gas and oil production wells
Table 1 Initial fluid distribution for all case sets (total model thickness $=500 \mathrm{~m}$ )

\begin{tabular}{lrlll}
\hline Case set & $h_{\mathrm{g}}(\mathrm{m})$ & $h_{\mathrm{w}}(\mathrm{m})$ & $h_{\mathrm{o}}(\mathrm{m})$ & Remark \\
\hline 1 & 0 & 250 & 250 & Undersaturated \\
2 & 50 & 250 & 200 & Saturated \\
3 & 100 & 250 & 150 & Saturated \\
4 & 134 & 250 & 116 & Saturated \\
5 & 158 & 250 & 92 & Saturated \\
6 & 181 & 250 & 69 & Saturated \\
7 & 200 & 250 & 50 & Saturated \\
8 & 240 & 220 & 40 & Saturated \\
9 & 290 & 172 & 38 & Saturated \\
10 & 316 & 149 & 35 & Saturated \\
11 & 338 & 134 & 28 & Saturated \\
12 & 355 & 122 & 23 & Saturated \\
\hline
\end{tabular}

simulations involved 36 different reservoir models, three of which are undersaturated.

\section{Well placement and controls}

For all the wells, the perforation interval covered $50 \%$ of the oil or gas column, as applicable. For the gas producer, the top of perforation was at the reservoir top, while the upper $50 \%$ of the gas column was completed (Fig. 2). In all cases, the gas producers are vertical wells.

In the cases of oil producer, the completions were also centralized to mitigate the effects of non-eccentricity. For vertical oil producer, the middle $50 \%$ of the oil column was perforated, i.e. equal stand-off from the initial gas-oil contact (GOC) and oil-water contact (OWC). However, in the case of horizontal oil producer, the same completion as described above for gas producer is applicable, the difference being that the horizontal well was placed at the middle of the oil column such that its toe and heel are equidistant from the nearest no-flow (sideway) boundaries of the model (see Fig. 2, as an example). For simplicity, we maintained these vertical and horizontal completion intervals $(50 \%$ of oil or gas column and model length for vertical and horizontal wells, respectively) for all the development concepts and simulation cases. To achieve realistic simulation results, some key production constraints were imposed on the wells (Table 2). In all the simulation cases, uptime was fixed at $100 \%$.

\section{Development concepts}

According to several authors (John et al. 2019; John 2017; Masoudi et al. 2013; Uwaga and Lawal 2006), common development concepts for oil-rim reservoirs include (1) oilonly, (2) OTG, (3) COG and (4) gas-only. Working with a 
Table 2 Some well controls used in the simulations

\begin{tabular}{|c|c|c|}
\hline Control & Constraint & Remark \\
\hline Max water cut (fraction) & 0.95 & Assumed technical limit for wellbore lifting \\
\hline Min bottom-hole pressure & $0.7 P_{\text {ri }}$ & Assumed maximum $30 \%$ drawdown from initial conditions \\
\hline Max gas-oil ratio & $3 R_{\mathrm{si}}$ & $\begin{array}{l}\text { Maximum allowable production of associated gas. Limit imposed to conserve } \\
\text { reservoir energy and mitigate potential gas-handling issues }\end{array}$ \\
\hline Max liquid rate (oil producer) & $0.2 N_{\mathrm{i}} / 365$ & Production limited to $20 \%$ of stock-tank oil initially in place (STOIIP) per annum \\
\hline Max gas rate (gas producer) & $0.2 G_{\mathrm{i}} / 365$ & Production limited to $20 \%$ of FGIIP per annum \\
\hline
\end{tabular}

Table 3 An outline of development concepts examined

\begin{tabular}{llll}
\hline $\begin{array}{l}\text { Group } \\
\text { concept }\end{array}$ & $\begin{array}{l}\text { Development } \\
\text { Oil column }\end{array}$ & Gas column \\
\hline 1 & Oil-only & Vertical well & Not applicable (N/A) \\
2 & OTG $\left(P_{\mathrm{r}}=0.95^{*} P_{\mathrm{ri}}\right)$ & Vertical well & Vertical well \\
3 & COG & Vertical well & Vertical well \\
4 & Oil-only & Horizontal well & N/A \\
5 & OTG $\left(P_{\mathrm{r}}=0.95^{*} P_{\mathrm{ri}}\right)$ & Horizontal well & Vertical well \\
6 & COG & Horizontal well & Vertical well \\
7 & OTG $\left(P_{\mathrm{r}}=0.90^{*} P_{\mathrm{ri}}\right)$ & Vertical well & Vertical well \\
8 & OTG $\left(P_{\mathrm{r}}=0.90^{*} P_{\mathrm{ri}}\right)$ & Horizontal well & Vertical well \\
9 & OTG $\left(P_{\mathrm{r}}=0.85^{*} P_{\mathrm{ri}}\right)$ & Vertical well & Vertical well \\
10 & OTG $\left(P_{\mathrm{r}}=0.85^{*} P_{\mathrm{ri}}\right)$ & Horizontal well & Vertical well \\
\hline
\end{tabular}

philosophy of maximizing oil or hydrocarbon (i.e. oil plus gas) recovery, the first three of the foregoing concepts were examined in this study. Although not evaluated explicitly, the gas-only concept is implicit in the results of the present study.

Oil-only was evaluated for all the 36 reservoir models, whereas COG and OTG could only be applied to the 33 saturated reservoir models. With the 10 subgroups of development concepts used in this study (Tables 1 and 3), a total of 336 simulation cases were executed to have a detailed understanding of the dynamics of the problem at hand.

For the OTG development concepts, the oil producer was closed, while the gas producer was opened when the reservoir pressure satisfied the condition, $P_{\mathrm{r}}=y P_{\mathrm{ri}}$. Here, variable $y$ is equal to $0.85,0.90$ or 0.95 , essentially depicting the effects of different drawdown limits on reservoir performance. $P_{\text {ri }}$ is the initial reservoir pressure. Figure 3 displays the simulation results for one of the cases investigated. In this example of a relatively weak aquifer, the expanding gascap is the primary drive mechanism, sweeping oil towards the horizontal producer.

\section{Measures of reservoir performance}

In most of the previous works on screening the performance of oil-rim reservoirs, a common feature is to

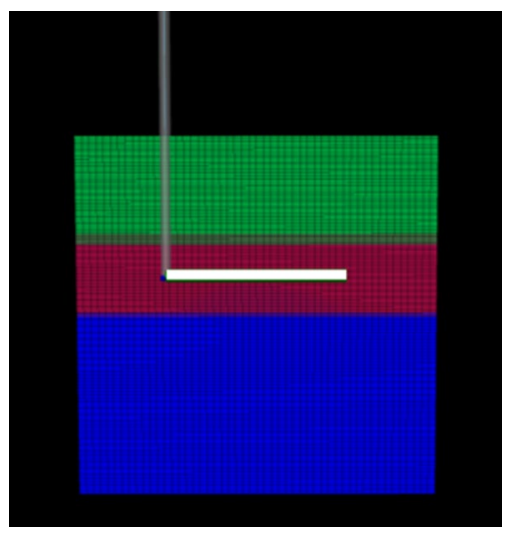

Fig. 3 A 2D view of the box model at the end of simulation for a case $\left(h_{\mathrm{g}}=440 \mathrm{ft} ; K=800 \mathrm{mD}\right.$; oil-only development with a horizontal oil producer). Colour notations are the same as described in Fig. 2

consider either UR or RF of oil as the basis for comparison and technical decisions. However, we consider the use of such a quantity as too simplistic and potentially misleading. The following are some shortcomings of using either oil UR or RF as the primary basis for screening different development concepts:

- The value of most oil-rim reservoirs is not necessarily limited to the oil, but both the oil and the associated gas (AG), considering that both are potential revenue sources.

- From an economic assessment standpoint, the present values of UR and RF are more relevant than their absolute values. For example, an option that has a well recovering 10 MMSTB in 10 years is more commercially attractive than another case in which the same well would recover 10 MMSTB in 15 years. In other words, the ability of a screening technique to account for the effect of potential production acceleration would improve its robustness for making business decisions about oil-rim reservoirs.

- Unlike some previous workers that used $m$-factor (ratio of initial gas-cap to oil-in-place volume at reservoir conditions) as the basis of gas-cap strength leaving out the aquifer strength (Lawal et al. 2010), we have employed 
the ratio of gas-cap to aquifer as the basis for quantifying potential threats to a sustainable oil recovery.

To address the foregoing drawbacks of previous screening techniques, we consider discounted UR, as against absolute UR. The discounted oil and gas URs are given by Eqs. 8 and 9. Because oil and gas are valuable, we also introduce discounted oil-equivalent (OE) volume, which converts the produced gas to its oil-equivalent volume in terms of the energy content (heating value). Equation 10 is the discounted UR of total hydrocarbon (in OE). In converting gas volume to its oil-equivalent, we assume $1 \mathrm{~m}^{3}$ oil $\approx 1015 \mathrm{~m}^{3}$ gas (Leibovitz 2018).

$N_{p}^{\prime}=\sum_{i=1}^{n} \frac{N_{p i}}{(1+r)^{i}}$,

$G_{p}^{\prime}=\sum_{i=1}^{n} \frac{G_{p i}}{(1+r)^{i}}$

$H_{p}^{\prime}=N_{p}^{\prime}+\frac{G_{p}^{\prime}}{1015}$

In addition, we introduce the corresponding discounted RFs as:

$R_{\mathrm{f}_{-} \text {oil }}^{\prime}=\frac{N_{p}^{\prime}}{N_{\mathrm{i}}} 100 \%$,

$R_{\mathrm{f} \_ \text {gas }}^{\prime}=\frac{G_{p}^{\prime}}{\left(G_{\mathrm{i}}+R_{\mathrm{si}} N_{\mathrm{i}}\right)} 100 \%$,

$R_{\mathrm{f} \_\mathrm{OE}}^{\prime}=\frac{H_{p}^{\prime}}{N_{\mathrm{i}}+\left(G_{\mathrm{i}}+R_{\mathrm{si}} N_{\mathrm{i}}\right) / 1015} 100 \%$,

where $G_{p i}=$ cumulative gas (solution plus free gas) produced in a year $i, G_{p}^{\prime}=$ discounted gas UR, $H_{p}^{\prime}=$ discounted total hydrocarbon (OE) UR, $i=$ producing year counter (dimensionless), $n=$ total number of production years (dimensionless), $N_{p i}=$ cumulative oil produced in year $i, N_{p}^{\prime}=$ discounted oil UR, $R_{\mathrm{si}}=$ initial solution gas-oil ratio, and $r=$ discount rate. The units of these quantities are indicated in the nomenclature section.

\section{Calculation and analysis procedure}

The steps taken to compute the key outputs $\left(E_{\mathrm{gw}}\right.$ and discounted RF) and formulate the screening guidelines are outlined as follows:
- After initializing the model, the values of $E_{\mathrm{gw}}, E_{\mathrm{go}}$ and $E_{\mathrm{wo}}$ were calculated (Eqs. 4, 5, 6 or 7).

- Post-simulation, the discounted (at 10\% discount rate) values of cumulative produced oil, gas and oil-equivalent for each case were calculated per Eqs. 8, 9 and 10, respectively.

- Discounted RFs of oil, gas and oil-equivalent were calculated per Eqs. 11, 12 and 13, respectively.

- Discounted RF was plotted versus $E_{\mathrm{gw}}, E_{\mathrm{go}}$ and $E_{\mathrm{wo}}$.

- From the resulting plots and for a given $E_{\mathrm{gw}}\left(E_{\mathrm{go}}\right.$ or $\left.E_{\mathrm{wo}}\right)$, the most robust (in terms of maximizing discounted RF of oil, gas or OE) development concept(s) can readily be identified, and the associated discounted RF for the hydrocarbon(s) of interest estimated.

\section{Results and discussion}

Due to space constraints, we limit the presentation of results to the relationships between discounted RF and $E_{\mathrm{gw}}$. However, it is easy to show that the qualitative deductions made from the individual hydrocarbon charts (discounted oil, AG or total hydrocarbon RF vs. $E_{\mathrm{gw}}$ ) are generally valid for the corresponding discounted RF versus $E_{\mathrm{go}}$ and discounted $\mathrm{RF}$ versus $E_{\text {wo }}$ charts.

\section{Discounted oil RF versus $E_{g w}$ to maximize accelerated oil recovery}

Figures 4 and 5 display the discounted oil RF versus $E_{\mathrm{gw}}$ curves for all the development concepts investigated using vertical and horizontal oil wells, respectively. The curves generally show that the discounted oil RF declines with increasing $E_{\mathrm{gw}}$. However, the declining trend becomes more pronounced and consistent from $E_{\mathrm{gw}}>3.0$ and $E_{\mathrm{gw}}>7.0$ for the vertical and horizontal wells, respectively. Based on these plots and experiences from field data, this deduction lends credence to the proposed hypothesis, which suggests that high relative mobile energy of the gas-cap poses a serious threat to oil recovery. As expected, under the same conditions, a horizontal oil producer consistently outperforms its vertical counterpart in maximizing discounted oil RF. Among other reasons, this superior performance of the horizontal well over its vertical counterpart is explained by the larger reservoir contact area, higher sweep efficiency and productivity index (hence lower pressure drawdown for the same production rate) offered by the former relative to the latter well type.

In selecting the optimum development concept and well type, the analyst simply considers the combination of concept and well type that yields the maximum discounted oil RF at a given $E_{\mathrm{gw}}$. Such combination is expected to be the most resilient against the threats posed by gas-cap and 


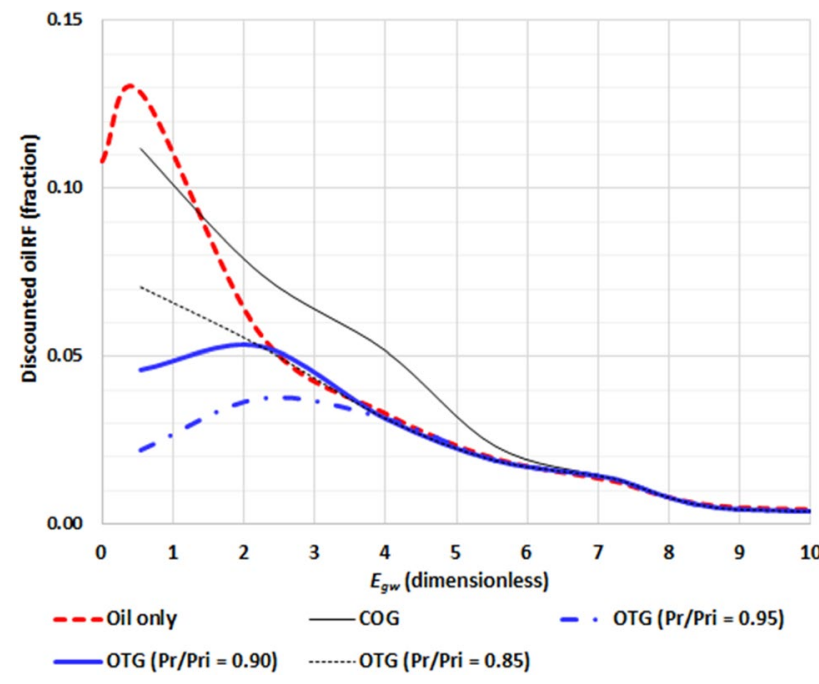

Fig. 4 Discounted oil RF versus $E_{\mathrm{gw}}$ (10\% discount rate) with vertical oil producers. Note that $E_{\mathrm{gw}}=0$ refers to the undersaturated cases

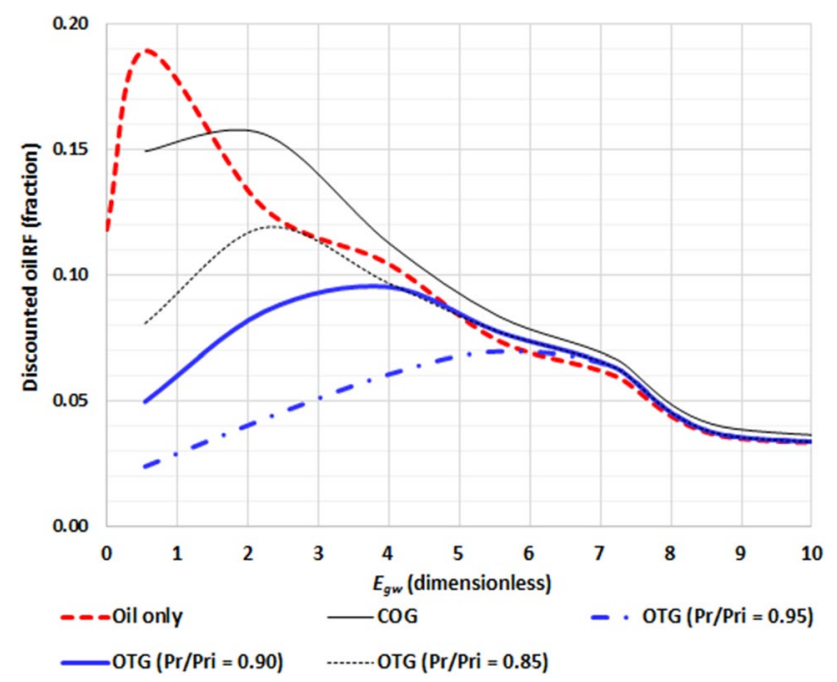

Fig. 5 Discounted oil RF versus $E_{\mathrm{gw}}(10 \%$ discount rate) with horizontal oil producers. Note that $E_{\mathrm{gw}}=0$ refers to the undersaturated cases

aquifer at that $E_{\mathrm{gw}}$. As an example, Figs. 4 and 5 show that the use of horizontal wells in an oil-only development scenario is the most attractive option to maximize oil recovery in a reservoir characterized by $E_{\mathrm{gw}}$ of 0.5 . But in the case of $E_{\mathrm{gw}}=2.0$, using a combination of horizontal oil and vertical gas producers in a COG development is recommended. The implementation of these recommended technical solutions is expected to yield maximum discounted oil RFs of $19 \%$ and $16 \%$ in the cases of $E_{\mathrm{gw}}=0.5$ and 2.0 , respectively. From $E_{\mathrm{gw}}>6.0$, any of the development concepts may be used, but the oil producers should be horizontal. However, the chart suggests that oil exploitation may not be very attractive when $E_{\mathrm{gw}}>6.0$, hence providing a justification to pursue gascap blowdown from inception in this case.

The performance results for the undersaturated oil reservoirs $\left(E_{g w}=0\right)$ are noteworthy. For both vertical and horizontal oil producers, the discounted oil RF increases with the ratio of relative mobile energy of gas-cap to aquifer up to $E_{\mathrm{gw}}=0.5$, after which it exhibits a negative correlation with $E_{\mathrm{gw}}$. The initial positive correlation between oil recovery and $E_{\mathrm{gw}}$ is attributed to the effect of the expanding gas-cap, complementing the aquifer in sweeping oil to the producer. This is a manifestation of the late response of the relatively less active gas-cap pushing back some of the attic oil, which the aquifer had initially pushed updip of the oil production well. However, above $E_{\mathrm{gw}}=0.5$, an active gas cap becomes increasingly detrimental to oil recovery, because the actively expanding gas cap becomes more suppressive of the aquifer, making it increasingly difficult for the aquifer to sweep a significant quantity of oil from the downdip area towards the producer.

In the OTG production case, regardless of the $E_{\mathrm{gw}}$ and well type, accelerated oil recovery declines with the reservoir pressure $\left(P_{\mathrm{r}} / P_{\mathrm{ri}}\right)$ at which production is automatically switched from oil to gas exploitation. This implies that the deeper the reservoir is depleted (lower the $P_{\mathrm{r}} / P_{\mathrm{ri}}$ ) during the prior phase of oil development before commencing a dedicated gas-cap blowdown, the better the oil recovery; providing such depressurization does not trigger undesirable negative consequences such as formation subsidence and the permeability-damaging effects of excessive compaction drive.

As another practical example, we consider 5\% discounted oil RF as an arbitrary target for minimum oil recovery. From Fig. 4, this target is best realized with vertical oil producers if COG is employed subject to a maximum $E_{\mathrm{gw}}$ of 4.0. Although oil-only and OTG $\left(P_{\mathrm{r}} / P_{\mathrm{ri}}=0.9\right.$ and 0.85$)$ are also good candidates, in this case, they stand a chance of meeting this target only if $E_{\mathrm{gw}}$ does not exceed 2.5. In comparison, based on Fig. 5, the use of horizontal wells offers much greater robustness to deploy any of the development options up to $E_{\mathrm{gw}}$ of 7.6.

\section{Discounted AG RF versus $E_{\text {gw }}$ to maximize accelerated AG recovery}

Figures 6 and 7 illustrate the discounted RF of AG (both solution and free gas) as a function of $E_{\mathrm{gw}}$ for all the development concepts evaluated, employing vertical and horizontal oil producers, respectively. Two distinct trends can be seen in these figures: one is for the development concepts that enhance gas-cap drainage (COG or OTG) and the other is for the development concept that forbids very high gas production (oil-only). It can be seen that under the same conditions, COG and OTG consistently outperform oil-only 


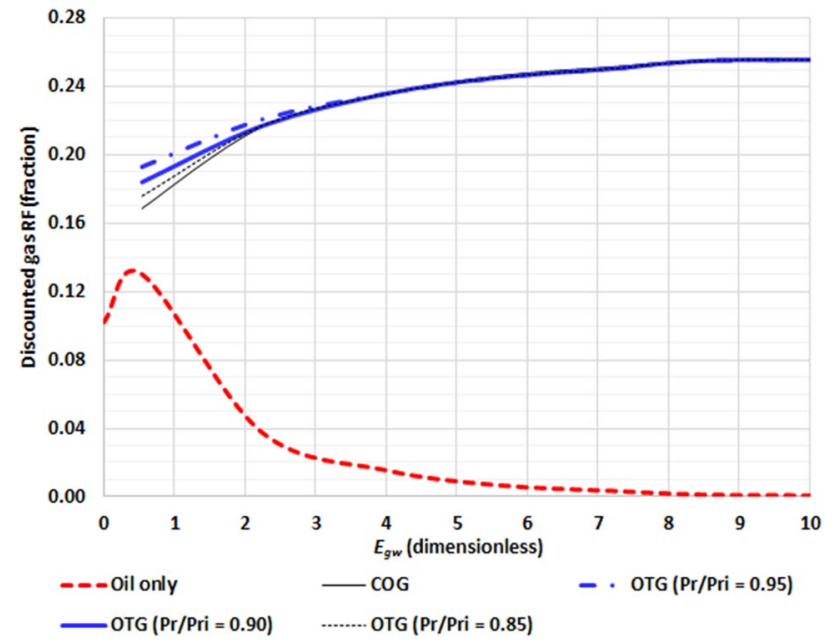

Fig. 6 Discounted AG RF versus $E_{\mathrm{gw}}(10 \%$ discount rate) with vertical oil producers. Note that $E_{\mathrm{gw}}=0$ refers to the undersaturated cases

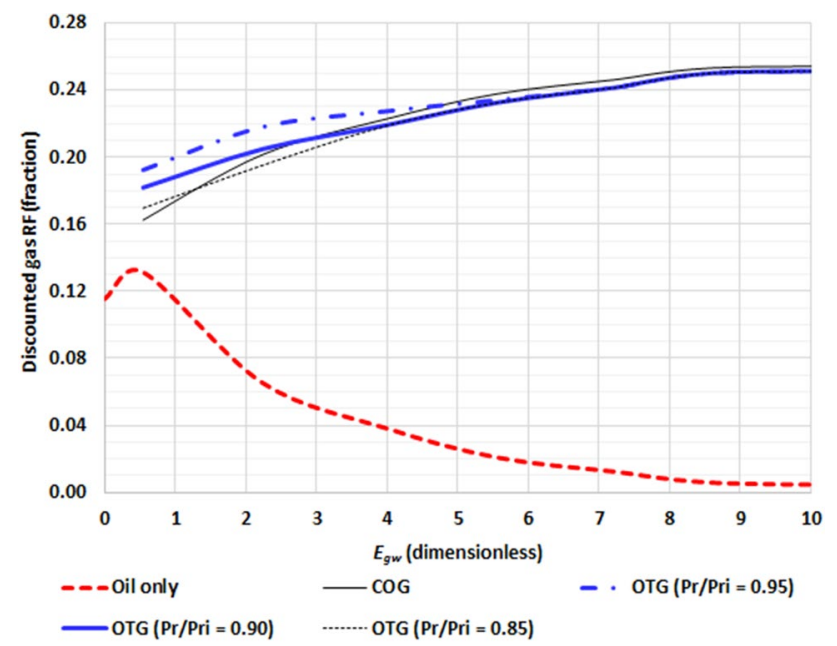

Fig. 7 Discounted AG RF versus $E_{\mathrm{gw}}(10 \%$ discount rate) with horizontal oil producers. Note that $E_{\mathrm{gw}}=0$ refers to the undersaturated cases

from the standpoint of maximizing discounted AG RF. However, when $E_{\mathrm{gw}} \geq 3.0$ for vertical wells and $E_{\mathrm{gw}} \geq 8.0$ for horizontal wells, the discounted AG RF peaks and there is no clear distinction between the performances of any two COG or OTG subgroups. These results are due to the AG recovery in both COG and OTG being driven primarily by a dedicated gas producer.

Therefore, in selecting the optimum development concept and well type to target AG recovery, we consider that combination of concept and well type yields the maximum discounted AG RF at a specified $E_{\mathrm{gw}}$. A comparison of the pair of Figs. 4 and 6 for vertical wells, as well as the pair of Figs. 5 and 7 for the horizontal counterparts, suggests that while the oil-only development concept is competitive for oil recovery, it is not most appropriate in cases where the maximization of accelerated AG recovery is the primary objective.

In the OTG production case, Figs. 6 and 7 show that accelerated AG production is sensitive to the reservoir pressure $\left(P_{\mathrm{r}} / P_{\mathrm{ri}}\right)$ at which production is switched from focused oil to gas exploitation. This implies that the deeper the reservoir is depleted (i.e. the lower the $P_{\mathrm{r}} / P_{\text {ri }}$ ) during the prior phase of oil development before commencing dedicated gas-cap blowdown, the poorer the subsequent discounted AG recovery. This deduction is valid for both vertical and horizontal well types.

\section{Discounted OE RF versus $E_{\text {gw }}$ to maximize accelerated total hydrocarbon recovery}

Figures 8 and 9 show the discounted OE RF versus $E_{\mathrm{gw}}$ curves for all the development concepts considered, when exploited with vertical and horizontal oil producers, respectively. From the standpoint of maximizing discounted OE $\mathrm{RF}$, it is evident that COG and OTG generally outperform their oil-only counterpart under the same conditions.

From Figs. 8 and 9, it is noteworthy that when $E_{\mathrm{gw}} \geq 6.0$, the difference between the performances of any two COG and/or OTG subgroups becomes less pronounced. Similar to the deduction made from Figs. 6 and 7, this suggests that from $E_{\mathrm{gw}} \geq 6.0$, reservoir depletion is dominated by the drainage of the primary gas-cap by the gas producer (or high GOR oil producer) and, as a result, the gas-only development is the appropriate option.

To select the optimum development concept and well type for a project that has the maximization of total hydrocarbon production as the primary objective, we consider that combination of concept and well type yields the maximum

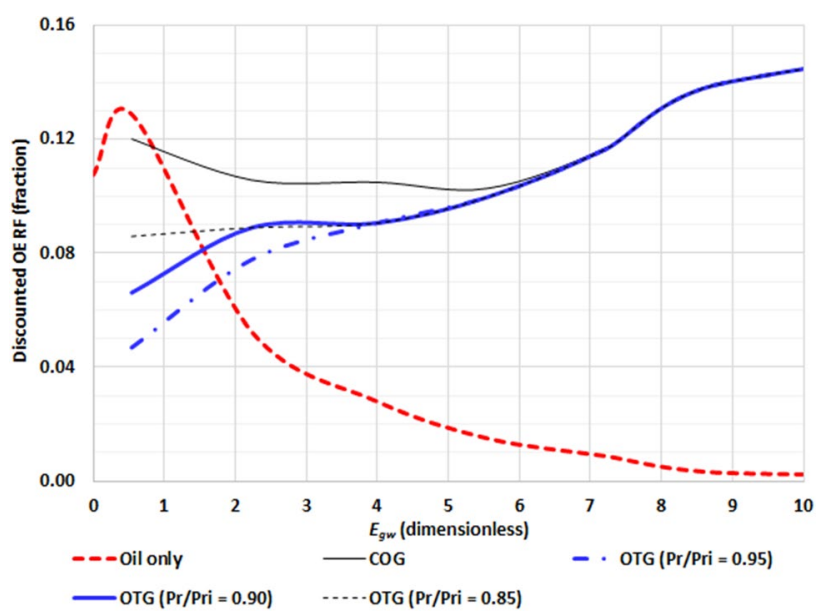

Fig. 8 Discounted OE RF versus $E_{\mathrm{gw}}$ (10\% discount rate) with vertical oil producers. Note that $E_{\mathrm{gw}}=0$ refers to the undersaturated cases 


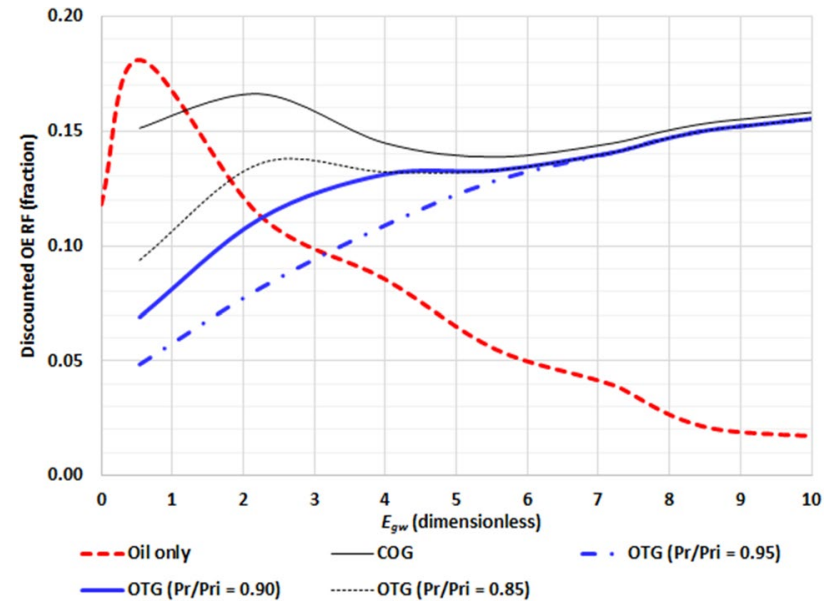

Fig. 9 Discounted OE RF versus $E_{\mathrm{gw}}(10 \%$ discount rate) with horizontal oil producers. Note that $E_{\mathrm{gw}}=0$ refers to the undersaturated cases

discounted OE RF at a representative $E_{\mathrm{gw}}$. Based on Figs. 8 and 9, the COG and OTG concepts become increasingly more competitive when $E_{\mathrm{gw}} \geq 2.0$ and $E_{\mathrm{gw}} \geq 3.0$, for vertical and horizontal producers, respectively.

\section{Application to mature oil-rim reservoirs}

In some cases, an oil-rim reservoir might have been produced for some time before considering the most suitable re-development concept to maximize the exploitation of remaining oil and gas in-place. In such a situation, some adjustments would have to be made to the computation of the $E_{\mathrm{gw}}$ to ensure that the estimated value is representative of the prevailing reservoir conditions. Drilling in-fill wells, side-tracking or re-completing existing wells are examples of cases that may warrant re-computing $E_{\mathrm{gw}}$ and evaluating the optimum exploitation plan for a mature oil-rim reservoir. Key decisions to be made on such re-development include (1) Should the objective of such well(s) be to maximize oil, AG or both? (2) Should the well(s) be mainly vertical or horizontal? (3) What maximum drawdown should be imposed without jeopardizing ultimate recovery?

To address the foregoing and other basic questions related to the exploitation of a brown oil-rim reservoir, Figs. 4, 5, 6, 7, 8 and 9 remain applicable. This notwithstanding, $E_{\mathrm{gw}}$ would have to be re-established for the new initial reservoir conditions.

By accounting for total produced volumes of oil, gas and water as well as in situ pressure, temperature and other variables (such as rock and fluid properties) at that instant, the adjusted $E_{\mathrm{gw}}, E_{\mathrm{go}}$ and $E_{\mathrm{wo}}$ are given by the following expressions:
$E_{\mathrm{go}}^{\prime}=\frac{G B_{\mathrm{g}} k_{\mathrm{rg}} h_{\mathrm{g}}^{\prime} \mu_{\mathrm{o}}}{N B_{\mathrm{o}} k_{\mathrm{ro}} h_{\mathrm{o}}^{\prime} \mu_{\mathrm{g}}}$

$E_{\mathrm{wo}}^{\prime}=\frac{W k_{\mathrm{rw}} h_{\mathrm{w}}^{\prime} \mu_{\mathrm{o}}}{N B_{\mathrm{o}} k_{\mathrm{ro}} h_{\mathrm{o}}^{\prime} \mu_{\mathrm{w}}}$

$E_{\mathrm{gw}}^{\prime}=\frac{G B_{\mathrm{g}} k_{\mathrm{rg}} h_{\mathrm{g}}^{\prime} \mu_{\mathrm{w}}}{W k_{\mathrm{rw}} h_{\mathrm{w}}^{\prime} \mu_{\mathrm{g}}}$,

where $B_{\mathrm{g}}, B_{\mathrm{o}}, \mu_{\mathrm{g}}, \mu_{\mathrm{o}}$ and $\mu_{\mathrm{w}}$ are the corresponding gas, oil and water properties at prevailing subsurface conditions. $G, N$ and $W$ are the corresponding free gas, oil and aquifer water remaining in-place. $h_{\mathrm{g}}^{\prime}, h_{\mathrm{o}}^{\prime}$ and $h_{\mathrm{w}}^{\prime}$ are the remaining effective thickness of gas, oil and aquifer zones, respectively.

Therefore, with relevant considerations given to produced volumes plus changes in petrophysical and fluid properties, updated relative mobile energies can be obtained as $E_{\mathrm{go}}^{\prime}, E_{\mathrm{ow}}^{\prime}$ and $E_{\mathrm{gw}}^{\prime}$. With these updated quantities, the engineer may proceed to use Figs. 4, 5, 6, 7, 8 and 9 as earlier described.

To facilitate the applicability of the new rapid screening technique, Fig. 10 shows a simple workflow that encompasses all the relevant steps required to be accomplished towards making informed decisions on the development and management of an oil-rim reservoir. Provision is also made for further and more detailed optimization of the outcome (development concept and well type) of the proposed rapid screening technique.

\section{Model validation}

The validity of the new oil-rim reservoir characterization parameter $E_{\mathrm{gw}}$ is tested using the history-matched E1 reservoir simulation model (Olamigoke and Isehunwa 2019). As reported by the original authors, the E1 reservoir model was built with the total dimension of $5029 \mathrm{~m}, 2134 \mathrm{~m}$ and $9 \mathrm{~m}$ in the $x$ - $y$ - and $z$-directions, respectively. The model has $33 \times 14 \times 20$ cells, equivalent to individual approximate cell dimensions of $152 \mathrm{~m} \times 152 \mathrm{~m} \times 0.5 \mathrm{~m}$. The grid was refined around the wells in all directions. Two-level local grid refinement was introduced $152 \mathrm{~m}$ from the wells in the $x$ - and $y$-directions, including the entire reservoir thickness in the $z$-direction. Figure 11 shows the E1 oil-rim 3D model with grid refinement. Based on the input dataset in Table 4, the $E_{\mathrm{gw}}$ parameter was estimated as 5.6. It is instructive to note that this example reservoir is more complex than the box model used to develop the new screening technique. As a minimum, the greater complexity of the example E1 reservoir is evident in its geometry and heterogeneity. Unlike the reference box model, which has a regular cuboid shape and 


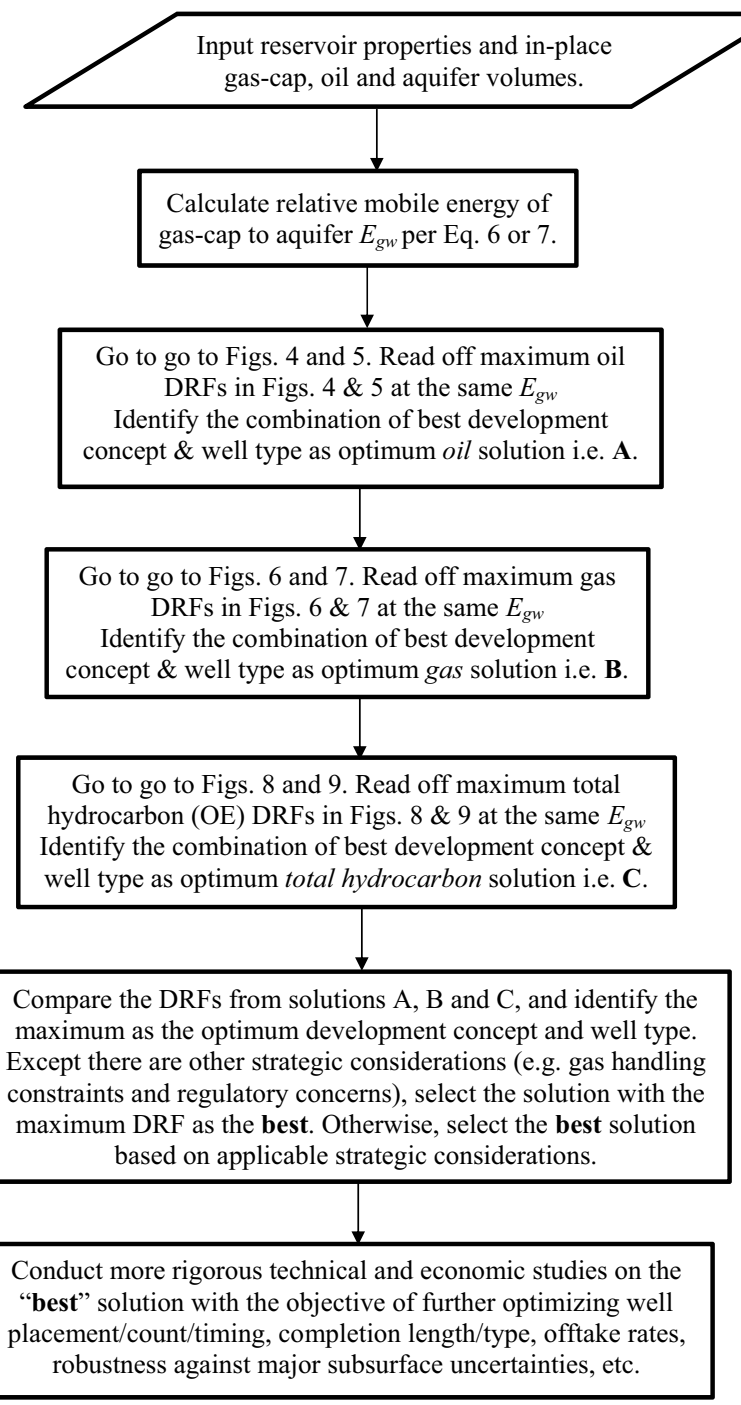

Fig. 10 A workflow to aid the implementation of the new technique of rapid screening of oil-rim reservoirs for development and management

is characterized by constant layer-cake petrophysical properties, the example reservoir has an irregular shape, while its petrophysical properties exhibit significant spatial variations, both vertically and horizontal. Due to its greater complexities, this example is considered a form of acid test for the new screening technique.

Considering either a vertical well or horizontal side track, three options for re-development were evaluated for the 9-m oil rim. These are oil-only, OTG and COG. The vertical well perforations and the lateral section of the horizontal well were placed midway in the remaining oil column. The crestal gas well for COG was produced at $10 \%$ of the free gas initially in place (FGIIP) per annum.

The reservoir simulation results (Table 5) show that for this brown oil-rim reservoir with $E_{\mathrm{gw}}$ of 5.6, the discounted

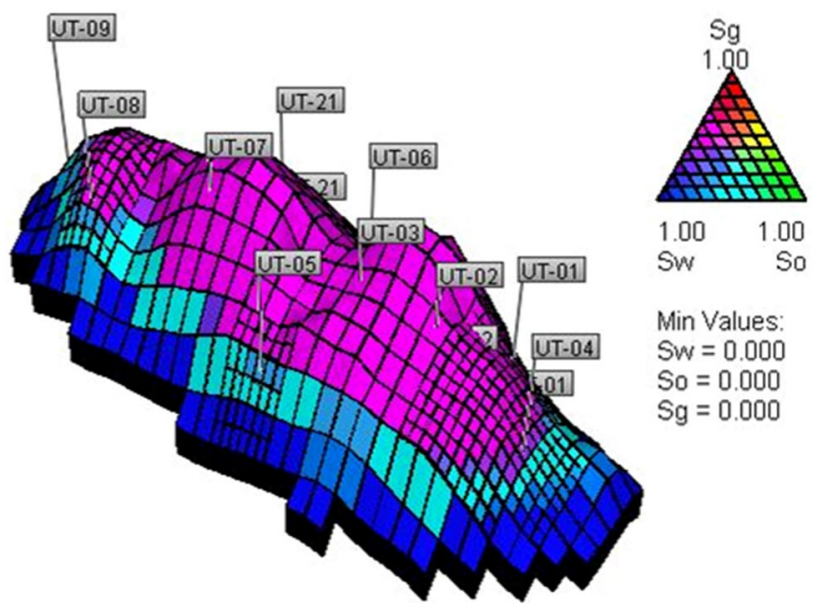

Fig. 11 A 3D view of the history-matched E1 model. The production wells are labelled, while the ternary diagram on the top right corner depicts the gas $\left(S_{\mathrm{g}}\right)$, oil $\left(S_{\mathrm{o}}\right)$ and water $\left(S_{\mathrm{w}}\right)$ saturations at any instant. Areas of intermediate saturations, which suggest reservoir sweep, are evident in various colour shades between the saturation bounds 0.0 and 1.0 as applicable

oil-equivalent recovery factors are maximized for $\mathrm{COG}$ regardless of the well type employed, while OTG is also quite competitive. In this case, oil-only is not a competitive option to maximize discounted oil-equivalent. It should be noted that while the limited production window for the remaining oil column and short reach of the horizontal sidetrack due to the reservoir structure impact on oil and gas recovery, the results obtained from the history-match model are nonetheless consistent, at least in qualitative terms, with the deductions from Figs. 8 and 9 at $E_{\mathrm{gw}}$ of 5.6.

Similarly, consistent with Figs. 4 and 5, the simulation results in Table 5 clearly indicate that the horizontal well outperforms its vertical counterpart in terms of maximizing oil recovery at $E_{\mathrm{gw}}$ of 5.6. However, given the objective to

Table 4 Summary of E1 reservoir model parameters

\begin{tabular}{ll}
\hline Variable & Value \\
\hline Oil-rim thickness, $h_{\mathrm{o}}$ & $9 \mathrm{~m}$ \\
Horizontal permeability, $K_{\mathrm{h}}$ & $2.467 \times 10^{-12} \mathrm{~m}^{2}$ \\
Oil viscosity, $\mu_{\mathrm{o}}$ & $0.9 \times 10^{-3} \mathrm{~Pa} \mathrm{~s}$ \\
Permeability anisotropy, $K_{\mathrm{v}} / K_{\mathrm{h}}$ & 0.01 \\
Oil formation volume factor, $B_{\mathrm{oi}}$ & $1.24 \mathrm{rm}^{3} / \mathrm{sm}^{3}$ \\
Gas formation volume factor, $B_{\mathrm{gi}}$ & $0.00404 \mathrm{rm}^{3} / \mathrm{sm}^{3}$ \\
End-point oil relative permeability, $K_{\mathrm{ro}}$ & 0.75 \\
End-point water relative permeability, $K_{\mathrm{rw}}$ & 0.80 \\
$m$ & 4.8 \\
$M$ & 36.42 \\
$E_{\mathrm{gw}}$ & 5.6 \\
\hline
\end{tabular}


Table 5 Simulated discounted recovery factors from $\mathrm{E} 1$ history-matched model

\begin{tabular}{|c|c|c|c|c|c|c|}
\hline \multirow{3}{*}{$\begin{array}{l}\text { Discounted recovery } \\
\text { factors }(\%)\end{array}$} & \multicolumn{6}{|c|}{ Development option } \\
\hline & \multicolumn{3}{|c|}{ Vertical well } & \multicolumn{3}{|c|}{ Horizontal well } \\
\hline & Oil-only & OTG & $\mathrm{COG}$ & Oil-only & OTG & $\mathrm{COG}$ \\
\hline$R_{\mathrm{f} \_ \text {oil }}$ & 2.50 & 2.50 & 2.14 & 3.01 & 3.01 & 2.23 \\
\hline$R_{\mathrm{f}_{\mathrm{fgas}}}$ & 1.77 & 29.38 & 36.12 & 0.57 & 28.57 & 35.97 \\
\hline$R_{\mathrm{f}_{-} \mathrm{OE}}$ & 1.98 & 17.65 & 21.34 & 1.49 & 17.39 & 20.43 \\
\hline
\end{tabular}

maximize gas recovery, the simulation results agree with Figs. 6 and 7 that the OTG and COG options offer greater value propositions than oil-only development for both vertical and horizontal completions in this example.

\section{Conclusion}

A new technique and set of performance-characterizing parameters $\left(E_{\mathrm{gw}}, E_{\mathrm{go}}\right.$ and $\left.E_{\mathrm{wo}}\right)$ have been formulated for screening the development and management of oil-rim reservoirs. The formulation accounts for the effects of well types, while its applicability covers the major exploitation objectives vis-à-vis maximizing accelerated recovery of oil, gas or total hydrocarbon. It also facilitates the decision on when to target oil versus gas production and the order that these resources should be exploited. Extensive numerical experiments covering different subsurface realizations and production constraints provide useful relationships between discounted recovery factor and the performance-characterizing parameter for common development options and well types.

From the resulting performance charts, useful insights are readily gained. Regardless of the $E_{\mathrm{gw}}$, it is found that vertical oil producers are generally suboptimal to exploit an oil rim. However, in oil-rim reservoirs characterized by low $E_{\mathrm{gw}}$ (aquifer dominates gas-cap drive), horizontal oil producers in an oil-only scenario offer the most competitive oil production. Conversely, oil-rim reservoirs with relatively high $E_{\mathrm{gw}}$ (gas-cap dominates aquifer drive) tend to yield lower accelerated oil production, even when COG is considered to dampen the production threats posed by the large and active primary gas cap in such situations.

The scope for accelerated AG production from oil-rim reservoirs increases with $E_{\mathrm{gw}}$, which enables maximizing gas-cap exploitation with a dedicated gas producer (either COG or OTG). Generally, a gas-only development is considered the most attractive when $E_{\mathrm{gw}} \geq 6.0$, which is a consequence of reservoir drainage being controlled strictly by the gas-cap when this threshold of the proposed performancecharacterizing parameter is exceeded. The example of a brown oil-rim reservoir demonstrates the applicability and robustness of the new screening technique.
To keep the problem tractable, some simplifying assumptions were made in the course of developing the proposed screening parameters and the performance correlations. In principle, the relaxation of all the assumptions promises improved robustness to the screening parameters. However, to minimize the additional computational costs while maximizing the incremental value, we recommend giving priority to the following scopes in the efforts to improve the robustness of proposed screening parameters and performance correlations.

- Effects of stand-off of the oil completion from both the gas-cap and aquifer. Current work is limited to mid-column completion.

- Effects of $K_{\mathrm{v}} / K_{\mathrm{h}}$, where the current formulation is premised on $K_{\mathrm{v}} / K_{\mathrm{h}}=0.1$.

- The distinction between bottom and edge water drives. The present study assumed the former.

- Further testing of the parameters in realistic reservoirs, which reflects appropriate heterogeneities.

Acknowledgements The authors are grateful to the Management of FIRST E\&P and its partners for supporting this study.

Open Access This article is distributed under the terms of the Creative Commons Attribution 4.0 International License (http://creativeco mmons.org/licenses/by/4.0/), which permits unrestricted use, distribution, and reproduction in any medium, provided you give appropriate credit to the original author(s) and the source, provide a link to the Creative Commons license, and indicate if changes were made.

\section{References}

Balogun O, Adepoju Y, Ogbuli A, Chukwunweike A (2015) Hydrocarbon resource development decision for gas reservoir with $10 \mathrm{ft}$ oil rim: Niger Delta case study. SPE paper 178382 presented at SPE Nigeria annual international conference and exhibition, Lagos, 4-6 Aug

Chan KS, Masoudi R, Karkooti H, Shaedin R, Othman M (2014) Smart horizontal well drilling and completion for effective development of thin oil-rim reservoirs in Malaysia. IPTC paper 17753 presented at international petroleum technology conference, Kuala Lumpur, 10-12 Dec 
Clarke AA, Ayton J, Lawton D, Lean JC, Burke K (2006) Case study: Lennox - the race to produce oil prior to gas cap blowdown. SPE paper 100126 presented at SPE Europec/EAGE annual conference and exhibition, Vienna, 12-15 Jun

Dilib FA, Jackson MD, Zadeh AM, Aasheim R, Arland K, Gyllensten AJ, Erlandsen SM (2015) Closed-loop feedback control in intelligent wells: application to a heterogeneous, thin oil-rim reservoir in the North Sea. SPE Res Eval Eng 18(1):69-83

Elharith M, Huey HY, Tewari RD, Claire L, Fawzi NSM, SchulzeRiegert R (2019) Integrated modelling of a complex oil rim development scenario under subsurface uncertainty. J Pet Explor Prod Technol 9(4):2417-2428

Fan Z, Cheng L, Song H, Wu X, Zhang A (2015) Fluid interface moving for the concurrent production of gas cap and oil ring of gas cap reservoirs. Pet Explor Dev 42(5):683-690

Garimella SVS, Kalbani A, Waili IH, Kasap E, Al-Lamki AA (2010) Gas blowdown case study: striking a fine balance between maximising gas production plateau and minimising oil loss. SPE paper 130596 presented at SPE Europec/EAGE annual conference and exhibition, Barcelona, 14-17 Jun

Irrgang HR (1994) Evaluation and management of thin oil column reservoirs in Australia. APPEA 34(1):64-78

Jaoua M, Rafiee M (2019) Optimization of oil production in an oil rim reservoir using numerical simulation with focus on IOR/ EOR application. SPE paper 196709 presented at SPE reservoir characterization and simulation conference and exhibition, Abu Dhabi, 17-19 Sept

John IJ (2017) Integration of static and dynamic reservoir properties for screening oil-rim development. MSc thesis, African Univ. Science and Technology, Abuja

John IJ, Matemilola S, Lawal K (2019) Simple guidelines for screening development options for oil-rim reservoirs. SPE paper 198718 presented at SPE Nigeria annual international conference and exhibition, Lagos, 5-7 Aug

Kabir S, Agamini MO, Holguin RA (2004) Production strategy for thin-oil columns in saturated reservoirs. SPE paper 89755 presented at SPE annual technical conference and exhibition, Houston, 26-29 Sept

Kromah MJ, Dawe RA (2008) Reduction of oil and gas coning effects by production cycling and horizontal wells. Pet Sci Technol 26(3):353-367

Lawal KA, Wells IA, Adenuga AO (2010) Preliminary assessment of oil-rim reservoirs: a review of current practices and formulation of new concepts. SPE paper 136955 presented at SPE Nigeria annual international conference and exhibition, Calabar, 31 Jul.-7 Aug

Lawal KA, Ovuru MI, Eyitayo SI, Matemilola S, Adeniyi AT (2016) An evaluation of underground storage as a potential solution for stranded associated gas in oil fields. SPE paper 184266 presented at SPE Nigeria annual international conference and exhibition, Lagos, 2-4 Aug

Lawal KA, Ovuru MI, Eyitayo SI, Matemilola S, Adeniyi AT (2017) Underground storage as a solution for stranded associated gas in oil fields. J Pet Sci Eng 150:366-375

Leibovitz DP (2018) Barrel of oil equivalent. en.m.wikipedia.org, retrieved 13 May 2019

Masoudi R, Karkooti H, Othman MB (2013) How to get the most out of your oil rim reservoirs? IPTC paper 16740 presented at international petroleum technology conference, Beijing, 26-28 Mar
Obidike P, Onyekonwu M, Ubani CE (2019a)“Exploitation of thin oil rim with large gas cap, a critical review. SPE paper 198724 presented at SPE Nigeria annual international conference and exhibition, Lagos, 5-7 Aug

Obidike P, Onyekonwu M, Ubani CE (2019b) Horizontal well standoff performance and exploitation of thin oil rim. SPE paper 198725 presented at SPE Nigeria annual international conference and exhibition, Lagos, 5-7 Aug

Obinna C, Anaevune A, Lewis H, Stow D (2016) An integrated approach to reservoir quality prediction of untapped oligocene reservoir offshore western Niger Delta. SPE paper 184273 presented at SPE Nigeria annual international conference and exhibition, Lagos, 2-4 Aug

Ogolo NA, Molokwu VC, Onyekonwu MO (2018) Techniques for effective oil production from thin oil rim reservoirs. SPE paper 193382 presented at SPE Nigeria annual international conference and exhibition, Lagos, 6-8 Aug

Olabode OA, Egeonu GI, Temiloluwa OI, Tomiwa O, Oreofeoluwa B (2018) Production forecast for Niger Delta oil rim synthetic reservoirs. Data Brief 19:2205-2214

Olamigoke O, Isehunwa SO (2019) Primary recovery factor correlations for thin oil rims with large gas caps. J Eng Sci Technol 14(4):2359-2371

Olamigoke O, Peacock A (2009) First-pass screening of reservoirs with large gas caps for oil rim development. SPE paper 128603 presented at SPE Nigeria annual international conference and exhibition, Abuja, 3-5 Aug

Silva JM-D, Dawe RA (2010) The challenge of producing thin oil rims in Trinidad. West Indian J Eng 32(1-2):36-41

Thomas P, Bratvold RB (2015) A real options approach to the gas blowdown decision. SPE paper 174868 presented at SPE annual technical conference and exhibition, Houston, 28-30 Sept

Udoh T, Akanji L, Vinogradov J (2018) Experimental investigation of potential of combined controlled salinity and bio-surfactant CSBS in enhanced oil recovery EOR processes. SPE paper 193388 presented at SPE Nigeria annual international conference and exhibition, Lagos, 6-8 Aug

Uwaga AO, Lawal KA (2006) Concurrent gas-cap and oil-rim production: the swing gas option. SPE paper 105985 presented at SPE Nigeria annual international conference and exhibition, Abuja, 31 Jul.-2 Aug

Vo DT, Waryan S, Dharmawan A, Susilo R, Wicaksana R (2000) Lookback on performance of 50 horizontal wells targeting thin oil columns, Mahakam Delta, East Kalimantan. SPE paper 64385 presented at SPE Asia Pacific Oil and Gas conference and exhibition, Brisbane, 16-18 Oct

Yeoh XQ (2014) Thin oil rim reservoir development. MSc thesis, Imperial College London

Ziablitckaia Y, Sharif A, Abdou M (2019) Co-development aspects of super giant reservoirs with condensate-rich gas cap. SPE paper 197200 presented at Abu Dhabi international petroleum exhibition and conference, Abu Dhabi, 11-14 Nov

Publisher's Note Springer Nature remains neutral with regard to jurisdictional claims in published maps and institutional affiliations. 